\title{
GENES, LENGUAJE, DIOSES. LA ENCRUCIJADA HUMANA
}

\author{
José Domingo Vilaplana Guerrero
}

\section{Huelva}

\begin{abstract}
Resumen: La ausencia de una definición universalmente compartida de lo humano favorece y hasta legitima en la actualidad no sólo todo tipo de intervención a nivel del genoma y sobre la naturaleza en su conjunto, con sacralizados propósitos eugenésicos, terapéuticos, y en general eudemónicos, sino la consolidación del programa transhumanista en cualquiera de sus versiones y su nada lejana expectativa de aplicación. Se trata quizá del último paso en la deriva naturalista, marcada por un ciego afán de dominio, propio de los dioses a los que el hombre aspira a sustituir. Esta suplantación de la divinidad por los hombres los nuevos dioses- puede conducir al nacimiento del relevo humano y, consiguientemente, a su progresiva desaparición por la doble vía de la superación sustitutiva y de la animalización esclavizadora y seriada. Desde antiguo el hombre juega a creerse un dios, tal ha sido el modo de conjurar su animalidad, sólo en apariencia asumida en la actualidad por un animalismo más ideológico que científico; sin embargo, es ahora cuando el desarrollo tecno-científico le permite saborear a estos curiosos animales los frutos de un poder que parece ilimitado, e incluso soñar con un mundo nuevo nacido de su propia creación. Paradógicamente, la claudicación animalista no parece contradecir el estertor transhumanista, quizá por ser ambos fruto de la misma fobia antihumana. He aquí lo que llamo "la encrucijada humana": ¿seguiremos empeñados en perseguir
\end{abstract}


la quimera que nos conducirá a la desaparición progresiva, primero como antropóforos ahítos, más tarde como reservorios biológicos para la replicación seriada según decisión de otros seres, ya difusamente imaginables, que nos habrán relevado en el señorío del planeta y acaso del universo? ¿O detendremos la ejecución del programa autolítico desde la plenificación de una autoconciencia estrictamente humana que nos visualice como dueños de nosotros mismos, pero a la vez como hermanos y como hijos de un mismo poder constitutivo, que nos otorga sentido, destino y valor?

Palabras clave: Transhumanismo, dioses, lenguaje, genes, encrucijada, evolución, dominio, relevo.

\section{Genes, languajes, gods. The human quandary}

Abstract: The current lack of a universally embraced definition of humankind favours and even legitimises not only all kind of interventions at the genome level and in nature as a whole, with idolised eugenic, therapeutic and in general eudaimonic purposes, but also the consolidation of the transhumanist programme in any of its versions and the not-so-distant prospect of its application. This is perhaps the last step in the naturalistic drift, characterised by a blind desire to dominate, typical of those gods man aspires to replace. The supplantation of divinity by men -the new gods- may lead to the birth of the human substitute and, consequently, to the gradual disappearance of mankind both through the development of enhanced substitutes and through a process of serial and enslaving animalization. From ancient times humans have pretended to be gods, thus warding off their animality, which is, at present, only apparently assumed by a more ideological than scientific animalism. Yet, now the techno scientific development allows these extraordinary creatures to savor the fruits of a seemingly unlimited power and even dream of a new world of their creation. Paradoxically, the renunciation of animalism does not seem to confront the throes of 
transhumanism, perhaps because both (views) are the result of the same anti human phobia. This is (indeed) what I call "the human quandary": will we insist on pursuing the chimera that will eventually lead us to our gradual disappearance, first as satiated anthropophora, later as biological reservoirs to be used for serial replications resolved by other beings, already vaguely unthinkable, who will have replaced us in the dominion of the planet and perhaps of the universe? Or will we halt the implementation of the autolytic project through the fulfilment of a truly human self-consciousness which envisages us as masters of ourselves, but at the same time as brethren and children of a single constitutive power granting us sense, destiny and courage?

Keywords: Transhumanism, gods, language, genes, quandary, evolution, dominion, substitute.

Recibido: 24/09/2017 Aprobado: 5/11/2017

No sé si calificar de sorprendente que los seres humanos no hayan producido a día de hoy una concepción de sí mismos, de lo que los distingue como humanos y los hace serlo, universalmente compartida. Lo sorprendente de esa carencia pudiera residir en el hecho de que entre las competencias que el hombre ha adquirdo en los últimos decenios de su historia, no tan larga en términos de tiempo evolutivo, se encuentre la capacidad de influir por mor de su inteligencia en los mecanismos de selección natural hasta poder sustituirlos o alterarlos al menos de tres maneras: mediante ingeniería biológica, mediante la ingeniería de ciborgs o mediante la ingeniería de vida inorgánica (Harari, 2014). Esta capacidad para intervenir rediseñando y reconduciendo lo que la evolución había modelado desde su supuesta ceguera no se ve acompañada del mismo éxito en la definición de lo humano y de parte al 
menos de lo que esa definición traería asociado, como sería alguna estrategia bien articulada para su propia defensa o conservación, de lo humano, digo. Al contrario: el hombre parece actuar perfectamente de espaldas al entendimiento de sí mismo; de hecho se produce la paradoja de que, por un lado, los psicólogos del bienestar miden los niveles de felicidad de las poblaciones según el autodiagnóstico que subjetivamente se hacen los encuestados, pero por otro lado toda la psicología terapéutica, de raíz freudiana, parte del supuesto de que la gente en verdad desconoce lo que le sucede porque en realidad se desconoce a sí misma. Ni como sujetos individuales ni como miembros de la especie que hemos llamado Homo sapiens sabemos con precisión o suficiente aproximación, y de manera compartida, lo que somos. Personalmente, me preocupa esta ignorancia, teñida incluso de contumacia sectaria, por cuanto abre un horizonte de incertidumbre respecto al propio destino de la Humanidad. Si por algo me interesa la exploración de lo que solemos llamar las fronteras o la frontera entre lo animal y lo humano no es tanto por alcanzar un sosiego personal, o por despejar una confusión incómoda, sino porque estoy persuadido de que esa carencia puede ser letal para la propia condición humana, para la subsistencia misma del ser humano. Como afirma Rodríguez Valls, "El ser humano, por decirlo así, se la juega en la interpretación que hace de sí mismo”. (R. Valls, 2017: 23) Es decir, tanto si renuncia a esa interpretación, como si yerra estrepitosamente en ella, el ser humano puede estar abocado a la pérdida de su condición, a la pérdida de su humanidad. Al olvido de lo humano, le seguirá la ausencia de lo humano. Tal es el riesgo transhumanista, por muy edulcorado que en ocasiones pueda 
presentarse, fundado —o enfundado- en equívocas teorías sobre la felicidad y la justicia cuyo rasgo más llamativo sigue siendo, precisamente, la carencia por claudicación de una concepción de lo humano, que sin embargo se complace en postular al hombre bien como animal enfermo, bien como animal divino capaz de autosuperarse. Sobre este asunto discurrirá mi pequeña aportación a este encuentro, a este foro de estudio y de reflexión compartida.

El debate en torno a lo que nos hace humanos en la actualidad está hipercapitalizado por la ciencia. Creo que esto es un hecho, por eso no podemos absolutamente prescindir de sus aportaciones, aunque sería disparatado rendirse a su veredicto. Así, se recurre a la ciencia para conocer no el estado de la cuestión en términos científicos, es decir hasta donde una metodología específica aplicada sobre un objeto específico de estudio logra pronunciarse en un momento dado, sino que se recurre a la ciencia para conocer el estado de la cuestión, a secas y en absoluto, como si de ninguna otra forma de aproximación intelectual se pudiera esperar alguna luz auténticamente iluminadora y, por tanto, legítimamente programática. No voy a discutir la idoneidad de, ni a establecer una competencia entre, otros saberes interesados en problemas como los que nos ocupan, pero sí es necesario reconocer que la versión científica es la que goza de un reconocimiento o valoración social, sobre todo en las sociedades occidentales, ostensiblemente mayor. Esto significa que la imagen que del ser humano postule la ciencia es la que irá calando, con todas las deformaciones y simplificaciones que sobre ella se inflijan, en el imaginario colectivo de unas sociedades, justo es reconocerlo, 
rehenes de un bienestar clamorosamente anestesiante. Sobre el olvido de lo humano opera, pues, la simplificación y la tergiversación como formas adulteradas de la propia visión científica, ya suficientemente sesgada. La popularización de la ciencia, por la vía de la tecnología aplicada a la vida cotidiana de los individuos y de las comunidades sociales, y por la vía del beneficio en términos médicos, como una promesa casi de inmortalidad, o de mortalidad indolora, lejana y, por supuesto, programada y asistida, es condición ineludible para que la alianza de la ciencia con el poder económico se mantenga y se perpetúe, de ahí el éxito mediático sin precedentes de que en la actualidad goza la divulgación científica, así como las campañas de recogida de fondos para emplearlos en la investigación biomédica. En lo que al hecho humano respecta esa divulgación científica y la propia ciencia han consagrado una visión del hombre en términos indiscerniblemente animales, hasta, como afirma Juan Arana, "cuestionar la especificidad del pensamiento respecto a cualquier otra función vital”, en un intento, nacido en la Modernidad y continuado en el siglo XX hasta la actualidad, por "borrar las fronteras que separan la vida de la no-vida [...] y también las que colocan al hombre en una posición especial” (Arana, 2014: 122-3). Pensamos, sí, pero eso no nos distingue singularmente, por tratarse de una diferencia de grado, no de esencia. Y si nos distingue, o en la medida que nos distinga, es debido al genoma que la evolución ha esculpido en nuestra especie, que ha logrado expresar una capacidad —el pensamiento consciente - de algún modo posibilitada a nivel molecular, y por tanto reductible a ello. Yuval Harari, después de hacer un recorrido por la evolución humana, formula la pregunta crucial: “¿Por qué es 
el género Homo el único en todo el reino animal que ha aparecido con estas enormes máquinas de pensar? [...] ¿Qué fue lo que impulsó la evolución del enorme cerebro humano durante estos dos millones de años?" (Harari, 2014: 21) (Cuenta Harari desde hace 2.5 millones de años, cuando comienza la evolución de Homo.) Y ofrece una respuesta: "Francamente, no lo sabemos". Pero en realidad no lo sabe a medias, ahí no juega limpio, porque cuando señala el acaecimiento de lo que llama "revolución cognitiva", la primera que lleva a cabo Homo sapiens, hace entre 70.000 y 30.000 años (luego vendrán la "revolución agrícola", hace 10.000 años, y recientemente la "revolución científica”, hace sólo 500 años) y se pregunta “¿Qué la causó?”, responde:

No estamos seguros. La teoría más ampliamente compartida aduce que mutaciones genéticas accidentales cambiaron las conexiones internas del cerebro de los sapiens, lo que les permitió pensar de maneras sin precedentes y comunicarse utilizando un tipo de lenguaje totalmente nuevo. Podemos llamarla la mutación del árbol del saber. ¿Por qué tuvo lugar en el ADN de los sapiens y no en el de los neanderthales? Fue algo totalmente aleatorio, hasta donde podemos decir. Pero es más importante comprender las consecuencias de la mutación del árbol del saber que sus causas. ¿Qué es lo que tenía de tan especial el nuevo lenguaje de los $s a-$ piens que nos permitió conquistar el mundo? (Harari, 2014: 35)

Harari, además de renunciar — aunque más parece una claudicación que una renuncia - al conocimiento de la causa que nos hizo seres diferentes, con el argumento chocante de que la consecuencia es más relevante que la causa, da por buena la hipótesis genética, además de la hipótesis del azar 
José Domingo Vilaplana

ciego, de la pura aleatoriedad, fiel, pues, el historiador al modelo explicativo del naturalismo canónico, del cientificismo. Todo, desde esta perspectiva, se lo debemos a la impronta azarosa que opera en un proceso evolutivo, ciego y selectivo, a pesar de estar demarcado por leyes físco-químicas, acaecido en un planeta a su vez surgido como consecuencia de la dinámica expansiva desencadenada tras el Big bang, esa eclosión primigenia, hace 13.500 millones de años, que dio paso a la formación de la materia y de las leyes y constantes que la hacen ser lo que es y rigen su funcionamiento. Entre las líneas de la cita de Harari entrevemos las siluetas de Monod, Dawkins, Chomsky, Pinker, entre otros señalados e influyentes investigadores. Páginas atrás, el propio Harari se preguntaba por el secreto del éxito de los sapiens:

¿Cómo conseguimos establecernos tan rápidamente en tantos hábitats tan distantes y ecológicamente tan diferentes? ¿Qué hicimos para empujar a las demás especies humanas a caer en el olvido? ¿Por qué ni siquiera los neanderthales, con un cerebro grande, fuertes y a prueba de frío, sobrevivieron a nuestra embestida? (Harari, 2014: 32)

Y termina: "El debate continúa. La respuesta más probable es lo mismo que hace posible el debate: Homo sapiens conquistó el mundo gracias, por encima de todo, a su lenguaje único". (Harari, 2014: 32)

Reparemos en que ese lenguaje único, desde la perspectiva evolutiva, se habilita desde una modificación genética que induce una transformación cerebral capaz de expresar esa nueva y exclusiva forma de lenguaje. Como el propio Harari afirma, hasta entonces el ser humano era un animal más, "sin 
importancia”, sin relevancia respecto al resto de animales, cosa que desde ese momento comienza a cambiar, hasta alcanzar la cumbre de la cadena trófica y desde ella el dominio sin competencia, en términos de uso y disfrute, de la naturaleza. La tesis del origen evolutivo, biológico y mutacional del lenguaje que Harari asume la encontramos en N. Chomsky y en S. Pinker, este último uno de sus más rendidos seguidores y exégetas. Pero ellos introducen un matiz no menor sobre el que Harari pasa por alto, quizá por no ser relevante para el propósito de su relato: para ambos, Pinker y Chomsky, el lenguaje que aprendemos es independiente de la estructura base que articula el pensamiento y posibilita el aprendizaje de las lenguas, de modo que no pensamos como hablamos o como nos expresamos, sino más bien expresamos a duras penas lo que pensamos o lo que somos capaces de pensar. Pinker y Chomsky niegan el determinismo lingüístico, niegan que pensemos en español, ruso o cherokee, o que esos idiomas lleven inserto algo así como un modo de estar en el mundo singularmente diferenciado entre sí que determine diferencias sustanciales en el esquematismo del pensamiento, en su gramática básica; pero por contra, su tesis consagra el carácter instintivo del lenguaje, algo así como un programa gramatical inscrito en el cerebro y localizado en algún lugar o región del mismo, común a todos los sapiens, sobre el que estos edifican las lenguas y los sistemas simbólicos de que se sirven para comunicarse. Ese programa base, al que Pinker llama "mentalés", implementado instintivamente en el ser humano, marca a su vez el instinto de aprender, de hablar y de entender las lenguas (Pinker, 2007: 17). Se trata de "una pieza singular de la maquinaria biológica de nuestro cerebro", que Pinker eleva, o hace descen- 
der, según se mire, a la condición de instinto: "Yo prefiero un término más pintoresco — dice - como «instinto», ya que esta palabra transmite la idea de que las personas saben hablar en el mismo sentido en que las arañas saben tejer sus telas”. (Pinker, 2007: 18) ¿Qué significa esto, qué consecuencias pudieran derivarse del carácter estrictamente biológico de la estructura matriz del lenguaje y de su activación instintiva? A mi juicio, tanto Pinker como Chomsky o Dawkins, que retrotraen el determinismo cultural al genético, vienen a decirnos, sí, que el lenguaje es un instrumento especializado con el que cuentan los humanos, pero al mismo tiempo, y quizá no inadvertidamente, sustraen tal instrumento del propio dominio humano: el hombre tan sólo usa el lenguaje, con la inmediatez automatizada e inconsciente del instinto. No poseemos, pues, al lenguaje, sino que éste nos posee a nosotros. En efecto, esa ausencia de consciencia de la lógica que subyace al despliegue del lenguaje, que "es cualitativamente igual en todos los individuos" y que "es muy distinto de las habilidades más generales que tenemos de tratar información o comportarnos de forma inteligente" (Pinker, ibidem), pretende que el mecanismo básico del pensamiento, en términos de su lógica gramatical, por tanto de cómo piensa y qué representaciones construye, no nos pertenece, antes al contrario: nos domina. El egoísmo del gen se traduce en egoísmo lingüístico. Así, el sujeto humano reaparece como un organismo integrado por subestructuras y subsistemas con capacidad de funcionamiento autónomo inconscientes de las funciones que realizan, si bien todas ellas armonizadas ponen en marcha eso que llamamos vida en cualquiera de sus formas, entre las que el ser humano, como ser vivo y además consciente, es una más. Única 
y exclusiva, sí; que nos distingue del resto de los seres vivos, sí; pero en cualquier caso seres diseñados por la evolución, es decir ciegamente y a merced del funcionamiento de sus mecanismos constitutivos, uno de ellos la gramática básica que habilita el pensamiento. (Por cierto, la tesis del lenguaje como instinto advierte Pinker que ya se encuentra en Darwin: "el hombre tiene tendencia instintiva a hablar..." (Darwin, 1970, El origen del hombre y la selección en relación al sexo, citado por Pinker, 2007: 20)

¿Qué son capaces de hacer, no obstante, estos seres, los humanos, productos exclusivos, como todos, del lento pulido evolutivo, con su exclusiva potencia intelectual? De momento diremos, con Pinker, que -oh, sorpresa - no son capaces de replicar el lenguaje humano, su propio lenguaje, con lo que más se refuerza la idea — para Pinker et al.— de estar poseídos por él: necesitamos - de hecho, dependemos- de un instrumento que no conocemos, a pesar de tanto como según Pinker sabemos sobre cómo pensamos y sobre cómo funciona la mente y el lenguaje; dice textualmente: "Hay muchos fenómenos del lenguaje que estamos empezando a entender casi tan bien como el funcionamiento de una cámara o para qué sirve el bazo"; no obstante, añade, "Nadie ha sido hasta la fecha capaz de hallar un órgano del lenguaje o un gen de la gramática, aunque la búsqueda continúa", como pone de manifiesto el descubrimiento y descripción de alteraciones neuronales y genéticas que afectan al lenguaje y no a la inteligencia, y también a la inversa (Pinker, 2007: 47). Se resiste, desde luego, el esclarecimiento de alguno de los atributos que nos hacen humanos, como es el funcionamiento de lo que 
nos hace pensar, pero no para señalar una frontera acaso infranqueable entre lo humano y lo no humano o animal, sino para mantenernos confinados en la cárcel de ignorancia de algo que opera a través de nosotros sometiendo nuestra existencia justamente en la dimensión que creíamos más nos liberaba del yugo de nuestra animalidad. Una vez más, ni por la vía del conocimiento, ni por la vía de la ignorancia, salimos de ella.

Sin embargo, y por aquí se dibuja el drama humano y se vislumbra la encrucijada en la que el hombre se encuentra, somos capaces de rediseñar inteligentemente lo que la evolución había diseñado, podemos intervenir tanto en la naturaleza como sobre nuestra ignota condición y modificarla, o como decía Harari, podemos alterar los mecanismos de la selección natural; pero, a imitación de esos mismos mecanismos, no sabemos con qué finalidad, ni qué nos impulsa a perpetrar tal alteración de un orden que necesitó milenios para forjarse, ni cuál sea la repercusión que tales rediseños tendrá para la Humanidad. Y no lo sabemos porque los mecanismos que operan en nosotros, según las interpretetaciones mecanicistas, deterministas y, en general, naturalistas, nos son desconocidos y nos dominan, por lo que estamos indefectiblemente a su merced, indefensos y sometidos a la paradójica condición de reos y verdugos, sin capacidad para impugnar la sentencia inscrita en nosotros mismos. Sorprende, desde esta perspectiva, la inconsistencia naturalista: de un lado proclama la explicación, hasta donde sea posible, de la conciencia o del funcionamiento de la mente (Dennet, Pinker), en coherencia con el credo cientificista de explicabilidad de todo lo real, es cuestión de tiempo, pero de otro lado insiste en la deconstrucción de lo humano en sus 
elementos constituyentes de modo que el hombre, sabiendo tanto, no sabe muy bien para qué lo sabe ni hacia dónde le direcciona su conocimiento, puesto que carece de auténtico dominio sobre sí como para decidir moral y responsablemente, es decir conscientemente, tal orientación... Los límites del conocimiento, pues, no redundan en una concepción de lo humano no naturalista, sino todo lo contrario: en la consideración del hombre como un autómata incapaz como tal de hacerse transparente para sí mismo; tal y no otro es el límite del conocimiento posible desde la perspectiva naturalista. El conocimiento, cabe decir, por tanto, no libera, sino tan sólo hace visibles las cadenas...

Percibo una cierta delectación en determinados ámbitos científicos y filosóficos en patrocinar una concepción del hombre estrictamente negativa, en el sentido de que en sí mismo reside la negación que lo aniquilará; un ser impotente, agonizante, o como, desde la más ortodoxa orilla filosófica, sentencia Alexander Kojève: "el hombre es una enfermedad mortal del animal" (citado por Agamben, 2010: 23); un ser consciente, pero para su tormento, sabedor de su carácter errado y de su fracasado destino. En efecto, Kojève, apoyado en la visión hegeliana de la historia, entiende que

...el hombre no es una especie biológicamente definida ni una sustancia dada de una vez para siempre: es, más bien, un campo de tensiones dialécticas cortado desde siempre por cesuras que separan en todo momento en su seno - por lo menos virtualmente - la animalidad antropófora y la humanidad que en ella se encarna. El hombre sólo existe históricamente en esta tensión: humano sólo pue- 
José Domingo Vilaplana

de serlo en la medida en que trasciende y transforma al animal antropóforo que le sostiene, sólo porque, mediante la acción negadora, es capaz de dominar y, eventualmente, de destruir su animalidad misma. (Agamben, 2010: 23)

El hombre como instrumento del Espíritu no es una idea extraña absolutamente a la idea del hombre rehén de lo que lo hace ser. En ambas visiones late la expectativa de la superación de esa condición cuando algo - el tiempo, la Historia, el programa genético- se haya consumado, es decir haya logrado superarse a sí mismo en un estadio final o terminal de la o de su historia. Para Kojève mientras haya animalidad antropófora, en un estadio posthistórico de lo humano, en privación pues de autoconsciencia, pervivirá todo lo que animalmente le satisfacía, algo que irónicamente equiparaba al american way of life, una forma de vida ahíta y primaria desde la inconsciencia. Postula Kojéve un devenir animal del hombre que necesariamente llevaría asociada la desaparición del lenguaje; y con tal desaparición, sostiene, no sólo el amor a la sabiduría, sino la misma posibilidad de sabiduría desaparecería. Esa reversión del hombre hacia su animalidad, lo que supondría la curación de su enfermedad, es visualizada por Harari en términos de reemplazo o sustitución, tal sería la superación, por los propios diseños inteligentes, híbridos o plenamente artificiales, que los humanos producen ciegamente, como movidos por una consigna fatal. En definitiva, es la sospecha de que el hombre lleve dentro de sí el programa que lo hace obsoleto, algo así como una obsolescencia programada, lo que late en la concepción idealista, al modo kojèviano-hegeliano, y naturalista, si admitimos la actividad humana como el resultado de la progresiva expresión de sus genes, entre las que se encuentra 
el instinto del lenguaje; un fenómeno, nuestra humanidad, que desconocemos pero sobre el que, no obstante, podemos intervenir... dramáticamente.

Pieza clave para que dicha intervención (auténtica cirujía invasiva) haya llegado a ser posible y continúe produciéndose es el lenguaje del pensamiento, como viene poniéndose de manifiesto desde todos los ámbitos del saber, pues todos han devenido lingúísticamente; sin el lenguaje nuestra capacidad de acción no hubiera pasado de la más elemental tecnología de supervivencia, con el lenguaje nos hemos convertido en pequeños dioses tarados, ciegos respecto al sentido de su propia obra. La secuencia que nos conduce hasta aquí es clara, epítome de la secuencia genes-lenguaje-dioses:

1. Estos seres, los humanos (autómatas que se creen libres, pero que no son sino meros productos evolutivos, como todo lo vivo), han experimentado unas revoluciones históricas (de raíz igualmente evolutiva y genética, por tanto imprevisible) que lo han singularizado hasta llegar a sentirse alejados irreversiblemente del animal sin importancia que fueron durante al menos dos millones y medio de años: aconteció entonces el hecho inédito (léase mutación) que activó tal proceso de singularización: alteraciones genéticas logran sin proponérselo unificar la condición humana en torno a una capacidad común regida por un esquematismo común, el lenguaje del pensamiento. El hombre, pues, adquiere su humanidad consciente por la vía de compartir un instinto nuevo: el lenguaje.

2. Pertrechado con ese instrumento, el hombre actual, el Homo sapiens, logró imponerse sobre el resto de los de su mismo género (revolución cogni- 
tiva); miles de años después se hace agricultor y ganadero (revolución agríco1a), lo que no se traduce necesariamente en una mejora de sus condiciones de vida ni aún menos de su felicidad, y algunos miles de años después propicia la eclosión de una nueva revolución, la científica, que actualmente lo proyecta quizá hacia su última y definitiva transformación sin que él mismo parezca dar muestras de haber detectado los síntomas de semejante expectativa programática...

3. La carencia de un concepto universalizado, unívoco e inequívoco de lo humano, a pesar de nuestra condición inteligente, nos convierte ante nosotros mismos en autómatas conscientes, vistos desde la perspectiva en gran angular que ofrece la historia universal y desde la fragmentación externalizante que promueve cierta ciencia y cierta filosofía muy influyentes; lo que llamamos libertad consciente, por tanto, no es sino una ilusión, una reverberación autoperceptiva, acaso provisionalmente útil y transitoria, pues es la expresión de la enfermedad que deberá ser superada, bien por regresión a una animalidad sana -álala e inconsciente-, o por sustitución o relevo transhumanista, conducente en el límite de su singularidad a la desaparición del hombre mismo.

Lo mantiene enceguecido y obnubilado, al hombre que se reconoce heredero del Renacimiento y la Ilustración, al hombre occidental que lidera y ostenta el poder tecnoeconómico, la sospecha arrogante de estar mutando en dioses: ésta es mi tesis. Y al hilo de ella, he aquí lo que formulo como "la encrucijada humana”: ¿seguiremos empeñados en perseguir la quimera que 
nos conducirá a la desaparición progresiva, primero como antropóforos ahítos, más tarde como reservorios biológicos para la replicación seriada según decisión de otros seres, hoy inimaginables, que nos habrán relevado en el señorío del planeta y acaso del universo? ¿ $\mathrm{O}$ detendremos la ejecución del programa autolítico desde la plenificación de una autoconciencia estrictamente humana que nos visualice como dueños de nosotros mismos, pero a la vez como hermanos y como hijos de un mismo poder constitutivo, que nos otorga sentido, destino y valor?

Dejando a un lado la discusión sobre si el pensamiento es independiente y previo al lenguaje, como postula Pinker, la tesis de estar poseídos por el lenguaje no es nueva, como tampoco la de nuestras aspiraciones olímpicas. Para Hermann Usener, filólogo y mitógrafo, especializado en religión griega clásica, "nuestro lenguaje piensa por nosotros", algo que para Emilio Lledó "es hoy día un presupuesto fundamental para todo trabajo sobre el lenguaje". También, para Eugen Coseriu, otro filólogo, "no es la lengua la que se determina por la realidad sino que, al contrario, es la realidad la que se concibe mediante la lengua”. A su vez, Nicolai Hartmann, ya desde la óptica del problema en términos filosóficos, afirma: "E1 individuo desconoce corrientemente hasta qué punto está dominado por el lenguaje, soporte del pensamiento". (Lledó, 2015: 57) Por su parte, la filosofía griega debatió a través del correoso concepto de naturaleza el grado de autonomía o dominio de sí que le es propio al ser humano, y sus respuestas nunca patrocinaron la idea de una efectiva libertad, capaz desde la autoconsciencia de ir más allá del conocimiento de lo que gobierna el mundo, es decir del conocimiento de lo 
José Domingo Vilaplana

que nos esclaviza, incluida la propia alma humana, híbrida de mortalidad e inmortalidad. Pero la sensibilidad griega hacia el problema del lenguaje es manifiesta, quizá por entender que nuestra relación con el mundo, con la naturaleza en cualquiera de sus formas o estadios, se establece a través del acceso que el lenguaje habilita, como señaló Platón en el Cratilo, primer tratado de filosofía del lenguaje, en el que trata de separar, precisamente, el pensamiento del lenguaje, o sea del onoma, del nombre, limitado y confuso en su capacidad de señalar o de acoger la ousía, la cosa real. Como vemos, ya sobrevuela en la reflexión platónica el peligro sofista de terminar siendo devorados por un bosque de palabras cuya convencionalidad constituya, precisamente, el falso espejo en el que mirarnos y desde cuyos errados reflejos orientar nuestro progreso hacia el fracaso final. Pero, qué duda cabe, el convencionalismo sofístico, su relativismo abierto y flexible, es lo que nos susurra la anhelada condición de dioses. Optar por adentrarnos en la aventura del conocimiento de la verdad ciertamente nos condena a asumir una condición siempre subsidiaria y subalterna respecto de esa verdad; rechazar esa búsqueda del conocimiento verdadero, por el contrario, nos convierte en creadores de la verdad misma, incluso de la realidad misma, y esa seducción, claro, nos arrastra, y a ella sucumbimos. Ni siquiera a Aristóteles le fue ajena esta tentación. Aporta Aristóteles una doble definición del hombre: "animal que tiene logos (en la doble acepción de lenguaje y razón) y animal politico". Se diferencia, pues, "de los animales en su capacidad de hablar y en su natural sociabilidad" (Rodríguez Donís, 2011: 140), esto es en el hecho de que no tienen lo hombres un modo unívoco y exclusivo de vivir y de relacionarse, a 
diferencia de los animales, sino que son modos cambiantes, dinámicos, en función de normas y leyes que se dan entre sí. Por ahí se entiende que en el Protréptico sugiera que el hombre es un dios mortal. Dice Aristóteles: "Nada de divino o bienaventurado, pues, le pertenece a los hombres, excepto lo único que es digno de esfuerzo, lo que hay en nosotros de entendimiento y sabiduría pues esto es lo único en nosotros que parece ser inmortal y divino" (Aristóteles, 2006: fr. 108), y continúa en el fragmento siguiente: "Y por poder participar de una facultad semejante, la vida, aun siendo por naturaleza miserable y difícil, sin embargo es gobernada tan agradablemente, que el hombre parece ser un dios en relación con los demás seres" (Aristóteles, 2006: fr. 109). Como sostiene Cicerón, respecto de Aristóteles, en De finibus bonorum et malorum (Del supremo bien y supremo mal): "el hombre, como un dios mortal, está hecho para dos actividades: entender y obrar" (Cicerón, 2004, citado por Rodríguez Donís, 2011: 141), a diferencia de los animales, que están hechos para una sola. Entender y obrar, capacidades que sugieren una sutil cercanía con crear. El propio G. Bruno se muestra afín a esta misma idea y a este mismo propósito, al declararse defensor del progreso y de la superioridad del hombre sobre los animales; dice en Spaccio della bestia trionfante: "los dioses han dado al hombre el intelecto y las manos y lo han hecho semejante a ellos, concediéndole el poder sobre los otros animales, que consiste no sólo en poder obrar sobre la naturaleza y lo ordinario, sino también por encima y fuera de las leyes de aquélla, a fin de que formando o pudiendo formar otras naturalezas, otros cursos, otros órdenes... viniese a constituirse un dios en la tierra”. (Bruno, G., 2011, citado por Rodríguez Donís, 2011: 
José Domingo Vilaplana

141) En pleno Renacimiento, un adalid del humanismo atribuye a la dotación intelectual del hombre, que lo emparenta con los dioses, la potencia que le permitirá constituirse en un dios sobre la tierra, precisamente por la vía de operar sobre la naturaleza, manipulando sus leyes para crear otras, "otros cursos, otros órdenes”. ¿Significa esto, para Bruno, que el hombre, en su condición superior a los animales, puede decidir responsablemente su acción sobre la tierra, una acción benéfica para sí y para la naturaleza, o por el contrario está inevitable y ciegamente impelido a intervenir porque así está determinado por los dioses que le han conferido su poderosa existencia y acaso le han engañado con la falsa promesa de llegar a ser uno entre ellos? Es difícil saber qué es lo que Bruno pensaba, pero es claro que el segundo término de la disyuntiva planteada está en línea con lo que el actual naturalismo, de raíz humanista e ilustrada, en coherencia con un idealismo que entroniza al hombre como ejecutor de una razón que lo supera, parece subliminalmente sugerir. El actual programa transhumanista se presenta como la nueva etapa de este itinerario conducente a la desaparición, bien por degeneración, bien por sublimación, de lo humano.

Como vemos, nada nuevo bajo el sol. Las sospechas cientificas de hoy hace tiempo que ya fueron sospechadas, y la tentación de dominar, aunque no sea sino una forma de confusa y diferida manipulación, expresa hoy como siempre el veneno de la soberbia humana. Pero quizá nunca como ahora el hombre necesita mirarse ante el espejo de su obra y decidir qué prefiere, si es que aún está a tiempo para decidir y no lo confunden los dioses: seguir sien- 
do humano, esto es profundizar en su humanidad, y redimirse a través de ella, o aspirar a un Olimpo que literalmente lo saca de sí y del mundo.

\title{
Bibliografia
}

G. Agamben, Lo abierto. El hombre y el animal, Valencia, Pre-Textos, 2015.

J. Arana, Limites de la biología y fronteras de la vida, Madrid, Unión Editorial, 2014.

Aristóteles, Protréptico, Madrid, Abada Editores, 2006.

P. Blom, Gente peligrosa. El radicalismo olvidado de la Ilustración europea, Barcelona, Anagrama, 2012.

G. Bruno, Expulsión de la bestia triufante. De los heroicos furores, Madrid, Siruela. Biblioteca de Ensayo, 2011.

M. T. Cicerón, Del supremo bien y supremo mal, Madrid, Gredos, 2004.

N. Chomsky, Reflexiones sobre el lenguaje, Barcelona, Ariel, 1979.

Ch. Darwin, El origen del hombre y la selección en relación al sexo, Madrid, Edaf, 1970.

Y. Harari, De animales a dioses, Barcelona, Debate, 2014.

E. Lledó, Filosofía y lenguaje, Barcelona, Crítica, 2015.

S. Pinker, El instinto del lenguaje, Madrid, Alianza Editorial, 2007.

—, Cómo funciona la mente, Barcelona, Debate, 2007.

M. Rodríguez Donís, "La naturaleza humana en Aristóteles", en: Fragmentos de filosofía, $\mathrm{n}^{\circ}$ 9, Sevilla, Universidad de Sevilla, 2011.

F. Rodríguez Valls, Orígenes del hombre, Madrid, Biblioteca Nueva, 2017.

\author{
José Domingo Vilaplana Guerrero \\ jdomingov@hotmail.com
}


